\title{
THE RELATIONSHIP BETWEEN COMMUNITY HEALTH BEHAVIOR AND AEDES AEGEPTY LARVA FREE INDEX IN ABELI, KENDARI, SOUTH EAST SULAWESI
}

\author{
Sulkarnain, Muhammad Asdin, Helvi Nugrahawati \\ Masters Program in Public Health, School of Health Sciences Mandala Waluya, Kendari
}

\begin{abstract}
Background: Dengue fever, also known as breakbone fever, is a mosquito-borne infection that can lead to a severe flu-like illness. It is caused by four different viruses and spread by Aedes mosquitoes. There are currently no vaccines. The best method of prevention is to avoid mosquito bites. Treatment is possible if diagnosis occurs before the patient develops dengue shock syndrome (DSS) or dengue haemorrhagic fever (DHF). The purpose of this study was to analyze the relationship between community health behavior and aedes aegepty larva free index in Abeli, Kendari, South East Sulawesi.

Subject and Method: This was a cross sectional study conducted at Abeli Community health center, Kendari, South East Sulawesi. A total sample of 248 household heads was selected for this study by simple random sampling. Household heads were selected from Abeli and Tondonggeu village, for each village was selected 124 household heads. The dependent variable was aedes aegypti larva free index. The independent variables were knowledge, attitude, and practice. The data were collected by questionnaire and observation sheet. The data were analyzed by chi square.

Result: In Abeli village, the associations between knowledge $(\mathrm{OR}=1.98$; CI 95\%=0.91 to $4.35 ; \mathrm{p}=0.120)$, as well as attitude $(\mathrm{OR}=0.99 ; 95 \% \mathrm{CI}=0.39$ to $2.48 ; \mathrm{p}=0.999)$ with aedes aegypti larva free index were statiscally not significant. The association between practice and aegypti larva free index $(\mathrm{OR}=2.55 ; 95 \% \mathrm{CI}=1.23$ to $5.30 ; \mathrm{p}=0.018)$ was statiscally significant. In Tondonggeu village, knowledge $(\mathrm{OR}=4.67 ; 95 \% \mathrm{CI}=2.15$ to 10.14; $\mathrm{p}<0.001)$, attitude $(\mathrm{OR}=2.43 ; 95 \% \mathrm{CI}=0.99$ to $5.93 ; \mathrm{p}=0.04)$, and practice $(\mathrm{OR}=5.49 ; 95 \% \mathrm{CI}=2.48$ to $12.18 ; \mathrm{p}<0.001)$ were associated with with aedes aegypti larva free index, and they were all statiscally significant.

Conclusion: Community health behavior is consistently associated with aedes aegypti larva free index. Community health knowledge and attitude are inconsistently associated with aedes aegypti larva free index.
\end{abstract}

Keywords: knowledge, attitude, action, aedes aegypti larva free index.

\section{Correspondence:}

Sulkarnain. Masters Program in Public Health, School of Health Sciences Mandala Waluya, Jl. A.H.Nasution No. G 37, Kendari, South East Sulawesi. Email: shul_dinkeskonut@yahoo.co.id. Mobile: 085255002719. 